\title{
Pars plana vitrectomy for malignant glaucoma in nonglaucomatous and in filtered glaucomatous eyes
}

This article was published in the following Dove Press journal:

Clinical Ophthalmology

26 November 2012

Number of times this article has been viewed

\section{Juliane Matlach \\ Joerg Slobodda \\ Franz Grehn \\ Thomas Klink}

Department of Ophthalmology, University of Wuerzburg,

Wuerzburg, Germany
Correspondence: Juliane Matlach Department of Ophthalmology, University of Wuerzburg, Josef-Schneider-Str II, D-97080 Wuerzburg, Germany

$\mathrm{Tel}+499312010$

Fax +49 931 20120490

Email j.matlach@augenklinik. uni-wuerzburg.de
Purpose: To assess the outcomes of pars plana vitrectomy for the treatment of malignant glaucoma in patients with and without previous filtration surgery.

Patients and methods: Data of 15 patients developing malignant glaucoma after trabeculectomy $(60 \%)$ or following ophthalmic interventions other than filtration surgery $(40 \%)$ were recorded retrospectively. Pars plana vitrectomy was performed in case of failed medical or laser treatment recreating the normal pathway of aqueous humor. The main outcome measures were the postoperative intraocular pressure (IOP), the frequency of complications, and success rate based on the following criteria: IOP reduction by $\geq 20 \%$ and to $\leq 21 \mathrm{mmHg}$ (definition one) or an IOP $<18 \mathrm{mmHg}$ (definition two) with (qualified success) and without (complete success) glaucoma medication.

Results: Vitrectomy reduced IOP from baseline in eyes with and without previous trabeculectomy during a median follow-up of 16.4 months (range 7 days to 58 months); although the majority of patients required glaucoma medication to reach desired IOP. The complete success rates were $11 \%$ (both definitions) for patients with filtering blebs and none of the patients without previous trabeculectomy had complete success at the 12-month visit. Complications were few and included transient shallowing of the anterior chamber, choroidal detachment, corneal decompensation, filtering bleb failure, and need for further IOP-lowering procedures.

Conclusion: Pars plana vitrectomy is equally effective for malignant glaucoma caused by trabeculectomy or interventions other than filtration surgery, although IOP-lowering medication is necessary in nearly all cases to maintain target IOP.

Keywords: ciliolenticular block glaucoma, malignant glaucoma, pars plana vitrectomy, trabeculectomy

\section{Introduction}

Malignant glaucoma is a rare but serious condition of secondary angle closure mostly seen after filtration surgery, but it may also occur spontaneously. ${ }^{1}$ It has also been described after laser iridotomy, ${ }^{2}$ laser capsulotomy, ${ }^{3}$ cataract surgery, ${ }^{4}$ topical miotic therapy, ${ }^{5}$ and blunt trauma. ${ }^{6}$ Some basic mechanisms of ciliolenticular block glaucoma are poorly understood. Lens disproportion and lens-ciliary body apposition in small eyes and anterior hyaloid changes with increased hydraulic resistance are supposed to be major pathophysiological factors. ${ }^{7}$ Besides these factors, poor vitreous flow and a tendency towards expansion of the choroidal volume in small eyes with angle closure refractory to iridotomy are further possible mechanisms of malignant glaucoma as proposed by Quigley et al. ${ }^{8}$ These features lead to aqueous misdirection into the vitreous cavity restricted by the anterior hyaloid membrane and additional forward 
movement of the lens-iris diaphragm. ${ }^{9,10}$ It is clinically characterized by an axial shallowing of the anterior chamber in the absence of a pupillary block mechanism, choroidal effusion, or hemorrhage, despite the presence of a patent iridectomy. ${ }^{11}$ Intraocular pressure (IOP) is usually dramatically increased, but may also be within the normal range. ${ }^{12}$ Treatment of malignant glaucoma should be done stepwise. Medical treatment includes topical antiglaucomatous medication, cycloplegic agents, aqueous suppressants, systemic carbonic anhydrase inhibitors, and hyperosmotic drugs inducing a posterior movement of the lens-iris diaphragm, reducing production of aqueous humor, and dehydrating the vitreous volume. ${ }^{13}$ The performance of laser capsulotomy, ${ }^{14}$ or laser anterior hyaloidectomy, ${ }^{15}$ and argon laser of ciliary processes through a peripheral iridectomy ${ }^{16}$ to relieve the ciliolenticular block are recommended for unsuccessful medical treatment. When medical and laser treatment failed, surgery should be performed to interrupt the ciliolenticular block. Pars plana vitrectomy in pseudophakic eyes or combined vitrectomy and cataract surgery in phakic eyes are effective methods to allow aqueous outflow into the anterior chamber. ${ }^{17,18}$ Apart from anterior vitrectomy alone or in combination with phacoemulsification ${ }^{17-19}$ or trabeculectomy ${ }^{20}$ via a posterior approach (pars plana), a procedure called zonulo-hyaloidovitrectomy through a peripheral iridectomy or iridotomy via the anterior chamber was described by Lois et al in $2001 .^{21}$ Due to the difficulty in visualization of the anterior hyaloid membrane in phakic eyes and the risk of damaging the lens, Chen et al published a new technique of videoendoscopeguided fluorescein-assisted vitrectomy in phakic eyes. ${ }^{22}$

In this study, a series of patients diagnosed with malignant glaucoma, who underwent pars plana vitrectomy to interrupt the ciliolenticular block mechanism, were reviewed. Major outcome measures were the event preceding malignant glaucoma, the efficacy of vitrectomy including success rate based on IOP reduction and need for medical treatment, and complications following vitrectomy in eyes with and without previous trabeculectomy.

\section{Material and methods}

\section{Patients}

Clinical records of 15 patients were reviewed retrospectively undergoing pars plana vitrectomy for treatment of malignant glaucoma at the University Eye Hospital of Wuerzburg, Germany between 1995 and 2010. The following parameters were recorded: age, sex, lens status, primary ophthalmic diagnosis, past medical history, glaucoma medication, and the event preceding malignant glaucoma.
Preoperatively, all patients received a standard ophthalmic examination including best corrected visual acuity measurement, applanation tonometry, slit lamp biomicroscopy, and indirect ophthalmoscopy.

Clinical inclusion criteria of malignant glaucoma were as follows: shallow anterior chamber in the presence of a patent iridectomy or iridotomy after a choroidal hemorrhage or effusion have been ruled out. Most of the patients had an increased IOP at the onset of malignant glaucoma. However, three patients were included according to the inclusion criteria despite having an IOP $<20 \mathrm{mmHg}$.

Patients were divided into a group with (Trab group) and one without (nonTrab group) previous trabeculectomy to evaluate the influence of vitrectomy on success of patients who had undergone filtration surgery before.

Success was defined as an IOP $\leq 21 \mathrm{mmHg}$ and IOP reduction by $\geq 20 \%$ (definition one) or an IOP $<18 \mathrm{mmHg}$ to baseline measures (definition two) with (qualified success) and without (complete success) IOP-lowering medication.

\section{Surgical technique}

Prior to surgical treatment, neodymium:yttrium-aluminiumgarnet (Nd:YAG) laser iridotomy was performed in all patients of the nonTrab group to rule out a pupillary block. Of these, three patients required additional surgical iridectomy for inconsistent iridotomy. As intensive medical treatment (including cycloplegic agents and topical and systemic IOP-lowering medication) remained unsuccessful and IOP was persistently elevated, pars plana vitrectomy became a prerequisite. A 20-gauge port was used in six patients of the Trab group and in all six patients of the nonTrab group and a 23-gauge port in three patients of the Trab group. Anterior vitrectomy via pars plana was performed using a three-port technique to disrupt the anterior hyaloid membrane ensuring aqueous outflow from the vitreous cavity into the anterior chamber in order to interrupt the ciliolenticular block mechanism. Existing adhesions and remnants of the vitreous body around the peripheral iridectomy were removed to allow patency for anterior aqueous flow. Vitrectomy was continued until the anterior chamber deepened. In phakic eyes with significant cataract, combined vitrectomy and cataract extraction were performed.

\section{Data analysis}

SPSS $^{\circledR}$ version 19.0 for Windows (IBM Corporation, Armonk, NY, USA) was used for statistical analyses and to create figures. Categorical variables were evaluated with Pearson's chi-squared test or Fisher's exact test. Differences between 
groups in single discrete variables of nonnormal distribution were tested for significance using the Mann-Whitney U test for small sample sizes. A maximum two-tailed $P$-value of $<0.05$ was considered an indication of statistical significance.

\section{Results}

The results of 15 patients undergoing anterior vitrectomy for treatment of malignant glaucoma during a 12-month follow-up are described.

\section{Baseline data}

Nine patients (Trab group) developed a ciliolenticular block following filtration surgery with a patent iridectomy in the absence of a pupillary block, hypotony, choroidal effusion or hemorrhage (Table 1). In six patients (nonTrab group), several intraocular surgeries, laser, or cyclodestructive treatments were performed prior to malignant glaucoma (Table 2). Malignant glaucoma occurred in seven patients after trabeculectomy and in two patients after combined trabeculectomy and cataract extraction. The median time between filtration surgery and malignant glaucoma was 41.4 days (range: 5-205 days). Of the patients in the nonTrab group, one patient developed a ciliolenticular block after neodymium:yttrium-aluminium-garnet (Nd:YAG) laser peripheral iridotomy five patients after cataract surgery. Mean time to malignant glaucoma was 14.0 days (range: 1-41 days) with one patient, who had a cataract extraction 9 years prior, excluded.

The mean age of six female and three male patients in the Trab group was 65 years (range: $41-88$ years). Four women and two men with a mean age of 78 years (range: $61-85$ years) were included in the nonTrab group and were significantly older than patients with filtering blebs $(P=0.046)$. Patients in both groups had a median axial length of $22.0 \pm 1.0 \mathrm{~mm}$ and $22.5 \pm 1.0 \mathrm{~mm}(P=0.383)$ with a median lens thickness of $4.8 \pm 0.9 \mathrm{~mm}$ and $4.6 \pm 0.7 \mathrm{~mm}(P=0.800)$, respectively.

Five patients in the Trab group and all the patients in the nonTrab group were pseudophakic at the time of diagnosing malignant glaucoma. Two phakic patients of the Trab group had combined cataract extraction while performing vitrectomy. Indications for combined surgery were a significant cataract and failed deepening of the anterior chamber during vitrectomy.

\section{IOP}

The mean IOP of patients in the Trab group was $25.0 \pm$ $9.3 \mathrm{mmHg}$ at the time of malignant glaucoma and was lower than in patients of the nonTrab group $(38.8 \pm 21.0 \mathrm{mmHg})$, although no statistical difference was found $(P=0.135)$. Figure 1 illustrates IOP development during follow-up for both groups. A reduction in IOP was observed after 12 months compared to baseline IOP for both groups. IOP was $20.0 \pm 3.9 \mathrm{mmHg}$ in the Trab group and $20.3 \pm 3.3 \mathrm{mmHg}$ in the nonTrab group at the 12-month visit. No statistical difference in IOP was found between the two groups $(P=0.571)$.

\section{Medication}

Preoperatively, patients of the Trab group received a total number of $2.0 \pm 1.3$ (range one to four) topical agents. Preoperatively, patients of the nonTrab group needed $3.0 \pm 1.3$ (range two to five) topical IOP-lowering drugs. Additional systemic medication (acetazolamide, mannitol) was necessary in all patients of both groups to lower IOP. The number of patients with IOP-lowering medication dropped to two patients in the Trab group needing 2.0 1.4 medication after 1 month. One patient in the nonTrab group was on 4.0 topical medications at the 1 -month visit. However, seven patients in

Table I Characteristics of nine patients with previous trabeculectomy (Trab group) undergoing vitrectomy for malignant glaucoma

\begin{tabular}{|c|c|c|c|c|c|c|c|c|c|}
\hline \multirow{2}{*}{$\begin{array}{l}\text { Patient/ } \\
\text { sex/ age/ } \\
\text { eye }\end{array}$} & \multirow{2}{*}{$\begin{array}{l}\text { Axial } \\
\text { length } \\
(\mathrm{mm})\end{array}$} & \multirow{2}{*}{$\begin{array}{l}\text { Pseudo- } \\
\text { phakic }\end{array}$} & \multirow{2}{*}{$\begin{array}{l}\text { Procedure } \\
\text { prior to } \\
\text { malignant } \\
\text { glaucoma }\end{array}$} & \multirow{2}{*}{$\begin{array}{l}\text { Time to } \\
\text { malignant } \\
\text { glaucoma } \\
\text { (days) }\end{array}$} & \multicolumn{2}{|l|}{ Baseline } & \multicolumn{2}{|l|}{ Last visit } & \multirow{2}{*}{$\begin{array}{l}\text { Follow- } \\
\text { up } \\
\text { (months) }\end{array}$} \\
\hline & & & & & $\begin{array}{l}\text { IOP } \\
(\mathrm{mmHg})\end{array}$ & $\begin{array}{l}\text { BCVA } \\
\text { (logMAR) }\end{array}$ & $\begin{array}{l}\text { IOP } \\
(\mathrm{mmHg})\end{array}$ & $\begin{array}{l}\text { BCVA } \\
\text { (logMAR) }\end{array}$ & \\
\hline I/f/75/R & - & Yes & Trab & 6 & 16 & 3.00 & 13 & 3.00 & 7 days \\
\hline $2 / f / 60 / L$ & 21.16 & Yes & Phaco-Trab & 13 & 24 & 0.40 & 18 & 0.10 & 37 \\
\hline $3 / f / 58 / R$ & 21.07 & Yes & Phaco-Trab & 17 & 23 & 0.70 & 14 & 0.20 & 13 \\
\hline $4 / f / 73 / R$ & 21.20 & Yes & Trab & 31 & 20 & 1.30 & 12 & 0.50 & 6 \\
\hline $5 / f / 4 I / L$ & 21.31 & No & Trab & 205 & 23 & 0.70 & 22 & 0.70 & II \\
\hline 6/m/49/L & 23.32 & No & Trab & 18 & 13 & 2.00 & 15 & 1.30 & 12 \\
\hline $7 / \mathrm{m} / 64 / \mathrm{L}$ & 22.63 & No & Trab & 5 & 44 & 1.30 & II & 0.40 & 58 \\
\hline 8/f/88/L & - & Yes & Trab & 5 & 30 & 3.00 & 22 & 3.00 & I4 days \\
\hline 9/m/73/L & 22.95 & No & Trab & 36 & 32 & 3.00 & 21 & 1.20 & 25 \\
\hline
\end{tabular}

Abbreviations: Trab, trabeculectomy; Phaco-Trab, combined trabeculectomy and phacoemulsification with posterior chamber intraocular lens implantation. 
Table 2 Characteristics of six patients without previous trabeculectomy (nonTrab group) undergoing vitrectomy for malignant glaucoma

\begin{tabular}{|c|c|c|c|c|c|c|c|c|c|}
\hline \multirow{2}{*}{$\begin{array}{l}\text { Patient/ } \\
\text { sex/age/ } \\
\text { eye }\end{array}$} & \multirow{2}{*}{$\begin{array}{l}\text { Axial } \\
\text { length } \\
(\mathrm{mm})\end{array}$} & \multirow{2}{*}{$\begin{array}{l}\text { Pseudo- } \\
\text { phakic }\end{array}$} & \multirow{2}{*}{$\begin{array}{l}\text { Procedure } \\
\text { prior to } \\
\text { malignant } \\
\text { glaucoma }\end{array}$} & \multirow{2}{*}{$\begin{array}{l}\text { Time to } \\
\text { malignant } \\
\text { glaucoma } \\
\text { (days) }\end{array}$} & \multicolumn{2}{|l|}{ Baseline } & \multicolumn{2}{|l|}{ Last visit } & \multirow{2}{*}{$\begin{array}{l}\text { Follow- } \\
\text { up } \\
\text { (months) }\end{array}$} \\
\hline & & & & & $\begin{array}{l}\text { IOP } \\
(\mathrm{mmHg})\end{array}$ & $\begin{array}{l}\text { BCVA } \\
(\log M A R)\end{array}$ & $\begin{array}{l}\text { IOP } \\
(\mathrm{mmHg})\end{array}$ & $\begin{array}{l}\text { BCVA } \\
\text { (logMAR) }\end{array}$ & \\
\hline I/f/83/R & 21.93 & Yes & $\mathrm{Phaco}^{\dagger}$ & $-\dagger$ & 40 & 3.00 & 21 & 3.00 & 12 days \\
\hline 2/f/77/L & - & Yes & Phaco & 9 & 30 & 1.30 & 10 & 1.30 & 13 \\
\hline $3 / f / 6 I / R$ & 21.87 & Yes & Nd:YAG I & 6 & 16 & 0.70 & 19 & 0.50 & 15 \\
\hline $4 / f / 8 I / R$ & 23.55 & Yes & Phaco & 41 & 31 & 1.50 & 25 & 1.00 & 31 \\
\hline $5 / \mathrm{m} / 80 / \mathrm{L}$ & - & Yes & Phaco & I & 78 & 3.00 & 8 & 1.30 & I \\
\hline $6 / \mathrm{m} / 85 / \mathrm{R}$ & - & Yes & Phaco & 13 & 38 & 1.30 & 20 & 3.00 & 23 \\
\hline
\end{tabular}

Note: ${ }^{\dagger}$ Cataract extraction was performed 9 years prior to malignant glaucoma.

Abbreviations: Phaco, phacoemulsification with posterior chamber intraocular lens implantation; Nd:YAG I, neodymium:yttrium-aluminium-garnet laser iridotomy.

the Trab group received a total of $2.3 \pm 0.8$ medications and four patients in the nonTrab group received $2.5 \pm 1.0$ medications at the last available visit of each patient (range: 7 days to 58 months). No statistical difference concerning pre- and postoperative IOP-lowering medication was found between the two groups during follow-up $(P=0.781)$.

\section{Success}

According to the criteria for qualified success, two (40.0\%) patients in the Trab group fulfilled both criteria of qualified success after 12 months (follow-up rate 55.6\%). None of the patients in the nonTrab group had an IOP $\leq 21 \mathrm{mmHg}$ and $\geq 20 \%$ reduction of IOP from baseline or an IOP

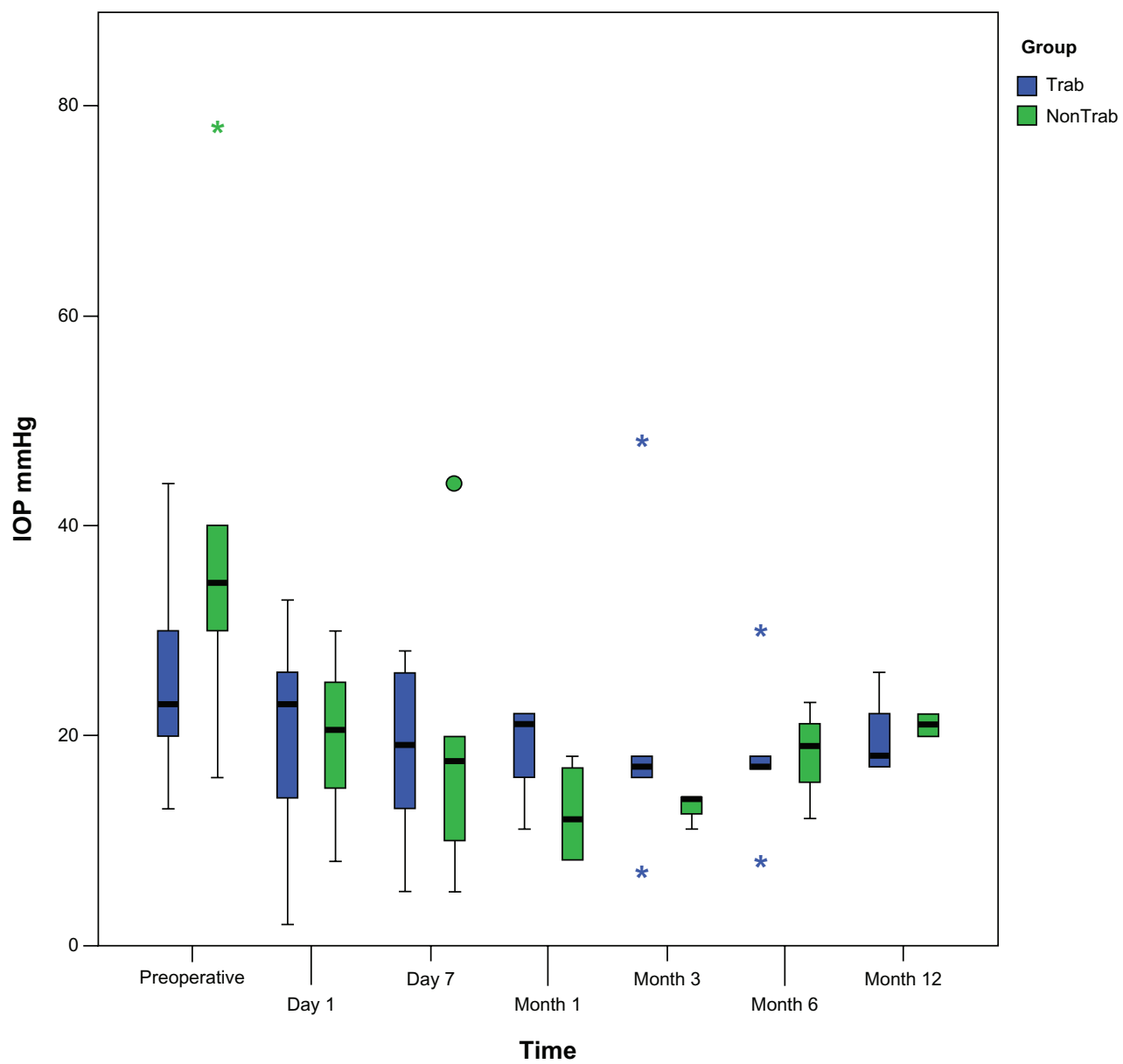

Figure I Development of intraocular pressure in patients with and without trabeculectomy prior to malignant glaucoma. Reduction of postoperative intraocular pressure was obtained during follow-up. Intraocular pressure was not statistically significant different between the two groups during follow-up.

Notes: Box plots illustrate the median (50th percentile) as a black center line and the 25 th and 75 th percentile as the lower and upper hinges of the box; circles represent minor outliers; stars represent major outliers.

Abbreviations: IOP, intraocular pressure; Trab, trabeculectomy. 
$<18 \mathrm{mmHg}$ with or without IOP-lowering medication (follow-up rate 33.3\%). Statistical analyses revealed no significant differences between the two groups (Table 3).

Complete success rate was $20.0 \%$ (one patient) according to both definitions (IOP $\leq 21 \mathrm{mmHg}$ and $\geq 20 \%$ IOP reduction; IOP $<18 \mathrm{mmHg}$ ) in the Trab group at the 12-month visit (follow-up rate 55.6\%). In the nonTrab group, none of the patients had complete success (follow-up rate $33.3 \%$ ). There was no statistical difference in complete success found between the two groups during follow-up (Table 3).

\section{Complications and further interventional management}

Pars plana vitrectomy was successful in terminating malignant glaucoma and facilitated intraoperative deepening of the

Table 3 Baseline data and outcomes of success at 6 and 12 months after pars plana vitrectomy

\begin{tabular}{|c|c|c|c|}
\hline & $\begin{array}{l}\text { Trab } \\
\text { group }\end{array}$ & $\begin{array}{l}\text { nonTrab } \\
\text { group }\end{array}$ & P-value \\
\hline \multicolumn{4}{|l|}{ Preoperative } \\
\hline IOP (mmHg) & $25.0 \pm 9.3$ & $38.8 \pm 21.0$ & $0.135^{\ddagger}$ \\
\hline $\begin{array}{l}\text { Number of IOP-lowering } \\
\text { medication }\end{array}$ & $2.0 \pm 1.3$ & $3.0 \pm 1.3$ & $0.130^{\ddagger}$ \\
\hline $\begin{array}{l}\text { Number of patients with } \\
\text { medication (\%) }\end{array}$ & $9(100.0)$ & $6(100.0)$ & \\
\hline \multicolumn{4}{|l|}{ At 6 months } \\
\hline Number of patients (\%) & $5(55.6)$ & $3(50.0)$ & \\
\hline IOP (mmHg) & $18.0 \pm 7.8$ & $18.0 \pm 5.6$ & $0.732^{\ddagger}$ \\
\hline \multicolumn{4}{|l|}{ Qualified success [n (\%)] } \\
\hline$\leq 21 \mathrm{mmHg}+20 \% \mathrm{IOP} \downarrow$ & $3(60.0)$ & $2(66.7)$ & $1.000^{\dagger}$ \\
\hline$<18 \mathrm{mmHg}$ & $3(60.0)$ & I (33.3) & $0.604^{\dagger}$ \\
\hline $\begin{array}{l}\text { Number of IOP-lowering } \\
\text { medication }\end{array}$ & $3.3 \pm 1.5$ & $3.5 \pm 2.1$ & $1.000^{\ddagger}$ \\
\hline $\begin{array}{l}\text { Number of patients with } \\
\text { medication (\%) }\end{array}$ & $3(60.0)$ & $2(66.7)$ & \\
\hline \multicolumn{4}{|l|}{ Complete success [n (\%)] } \\
\hline$\leq 21 \mathrm{mmHg}+20 \% \mathrm{IOP} \downarrow$ & $2(40.0)$ & I (33.3) & $1.000^{+}$ \\
\hline$<18 \mathrm{mmHg}$ & $2(40.0)$ & $0(0.0)$ & $0.486^{\dagger}$ \\
\hline \multicolumn{4}{|l|}{ At 12 months } \\
\hline Number of patients (\%) & $5(55.6)$ & $2(33.3)$ & \\
\hline IOP (mmHg) & $20.0 \pm 3.9$ & $20.3 \pm 3.3$ & $0.57 \mathrm{I}^{\dagger}$ \\
\hline \multicolumn{4}{|l|}{ Qualified success [n (\%)] } \\
\hline$\leq 21 \mathrm{mmHg}+20 \% \mathrm{IOP} \downarrow$ & $2(40.0)$ & $0(0)$ & $0.486^{\dagger}$ \\
\hline$<18 \mathrm{mmHg}$ & $2(40.0)$ & $0(0)$ & $0.486^{\dagger}$ \\
\hline $\begin{array}{l}\text { Number of IOP-lowering } \\
\text { medication }\end{array}$ & $2.8 \pm 1.3$ & $4.0 \pm 2.8$ & $0.800^{\ddagger}$ \\
\hline $\begin{array}{l}\text { Number of patients with } \\
\text { medication (\%) }\end{array}$ & $4(80.0)$ & $2(100.0)$ & \\
\hline \multicolumn{4}{|l|}{ Complete success [n (\%)] } \\
\hline$\leq 21 \mathrm{mmHg}+20 \% \mathrm{IOP} \downarrow$ & I (20.0) & $0(0)$ & $1.000^{\dagger}$ \\
\hline$<18 \mathrm{mmHg}$ & I (20.0) & $0(0)$ & $1.000^{\dagger}$ \\
\hline
\end{tabular}

Notes: 'Pearson's chi-squared test (Fisher's exact test); ${ }^{\dagger}$ Mann-Whitney $U$ test; values are means \pm standard deviation unless otherwise stated.

Abbreviations: IOP, intraocular pressure; Trab, trabeculectomy. anterior chamber in all cases. The incidence of complications and surgical revisions are shown in Table 4.

Three of nine patients $(33.3 \%)$ in the Trab group had transient hypotony (defined as an IOP $<5 \mathrm{mmHg}$ ) for a mean duration of $3.3 \pm 3.2$ days (range: $1-7$ days). Of these, the 23-gauge approach was used for vitrectomy in two patients. All three patients with filtering blebs suffering from hypotony had a choroidal detachment for a duration ranging 3-9 days. Postoperative hypotony lasting $>10$ days without choroidal detachment was seen in one patient $(16.7 \%)$ of the nonTrab group. There was no statistical difference in length of hypotony between both groups $(P=0.500)$. In four patients (44.4\%) of the Trab group, anterior chamber flattened again for 1-7 days postoperatively and deepened spontaneously thereafter without further interventions. In contrast, in two patients (33.3\%) of the nonTrab group, the anterior chamber was shallow for 3 days after vitrectomy, deepened spontaneously, and remained deep thereafter. Further adverse events were failure of filtering blebs in four patients and progression of cataract in two patients of the Trab group. Neither choroidal effusion, blebitis, endophthalmitis, nor iris incarceration was seen in either group during follow-up.

Incidence of further surgical interventions including cyclodestructive procedures and revitrectomy is summarized in Table 4. In five patients (55.6\%) of the Trab group and in three patients (50\%) of the nonTrab group, one or more additional IOP-lowering procedures were necessary. In three patients of the Trab group, four diode cyclophotocoagulations and cyclocryocoagulations were performed,

Table 4 Incidence of postoperative complications and further interventions

\begin{tabular}{llll}
\hline & $\begin{array}{l}\text { Trab } \\
\text { group }\end{array}$ & $\begin{array}{l}\text { nonTrab } \\
\text { group }\end{array}$ & P-value $^{\dagger}$ \\
\hline Hypotony $(<5 \mathrm{mmHg})$ & $3(33.3)$ & $\mathrm{I}(\mathrm{I} 6.7)$ & 0.604 \\
$\quad$ Duration (range) & $\mathrm{I}-7$ days & I0 days & 0.500 \\
Shallow anterior chamber & $4(44.4)$ & $2(33.3)$ & 1.000 \\
Choroidal detachment & $3(33.3)$ & - & 0.229 \\
$\quad$ Duration (range) & $3-9$ days & - & \\
Corneal decompensation & $3(33.3)$ & $2(33.3)$ & 1.000 \\
Progression of cataract & $2(22.2)^{\#}$ & $-{ }^{\ddagger}$ & 0.486 \\
Conjunctival leakage & $\mathrm{I}(\mathrm{II} .1)$ & - & 1.000 \\
Choroidal effusion & - & - & - \\
Iris incarceration & - & - & - \\
Blebitis/endophthalmitis & - & - & - \\
Additional procedures & & & \\
$\quad$ Diode cyclophotocoagulation & $4(44.4)$ & $2(33.3)$ & 1.000 \\
Cyclocryocoagulation & $4(44.4)$ & $3(50.0)$ & 1.000 \\
Revitrectomy & $\mathrm{I}(\mathrm{II} . \mathrm{I})$ & - & 1.000 \\
\hline
\end{tabular}

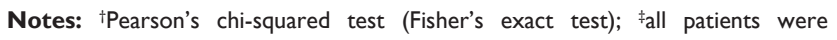
pseudophakic at the time of vitrectomy; "two patients remained phakic after initial vitrectomy; data represents absolute values (percentage).

Abbreviation: Trab, trabeculectomy. 
respectively. Two patients in the nonTrab group needed diode cyclophotocoagulation and three patients received cyclocryocoagulation. No statistical difference regarding complications or surgical revisions was found between the two groups.

\section{Discussion}

Ciliolenticular block glaucoma remains one of the most challenging serious adverse events necessitating immediate treatment to reduce aqueous misdirection into the vitreous and consecutive displacement of the lens-iris diaphragm. In a recent review by $\mathrm{Ng}$ and Morgan, different pathophysiological features are described to play an important role for development of ciliolenticular block glaucoma, although not every part is clearly understood. ${ }^{7}$ Lens disproportion and lens-ciliary body apposition in at-risk eyes (hyperopic, nanophthalmic) and anterior hyaloid changes with increased hydraulic resistance due to a strong adhesion between vitreous, lens, and ciliary body are major pathogenic factors. ${ }^{7}$ In angle closure eyes, the lens is disproportionally large and increases in size, thereby pushing the iris and ciliary body forwards. In addition, as the lens-ciliary body distance decreases, the fluid resistance increases and aqueous humor passes through the anterior vitreous restricted by the anterior hyaloid. Moreover, lens apposition to the ciliary body may lead to reduced aqueous flow into the anterior chamber. Both lens disproportion and lens-ciliary body apposition result in forward movement of the lens-iris diaphragm and a shallow anterior chamber. ${ }^{7}$ Since malignant glaucoma also occurs in aphakic eyes, the lens seems not to be the only cause. Flow resistance increases as the aqueous humor passes through the vitreous body and compresses the anterior hyaloid face. The pressure differential between the anterior and posterior chamber leads to an anterior displacement of iris and ciliary body. Quigley et al described poor vitreous flow and a tendency towards expansion of the choroidal volume in small eyes with angle closure refractory to iridotomy as possible mechanisms of malignant glaucoma. ${ }^{8}$

Anterior vitrectomy for malignant glaucoma refractory to medical and laser treatment facilitates aqueous humor outflow into the anterior chamber and reflects one recognizing pathophysiologic role of the vitreous in the mechanism of malignant glaucoma. ${ }^{7,23,24}$ Results of vitrectomy in pseudophakic and aphakic eyes developing malignant glaucoma have been published in several previous studies. ${ }^{18-22,25,26}$ Nevertheless, vitrectomy alone in phakic eyes may be disappointing due to the difficulty in visualization and removal of the anterior hyaloid membrane without lens damaging. ${ }^{18,25,26}$ Therefore, combined cataract extraction and vitrectomy even in eyes without lens opacities or mild lens opacities are strongly recommended.

In this study of 15 patients diagnosed with malignant glaucoma, the efficacy and safety of pars plana vitrectomy for treatment of the ciliolenticular block was evaluated. The results were based on data of patients with and without previous filtration surgery during a median follow-up of 16.4 months. It was found that vitrectomy for malignant glaucoma was successful in IOP reduction after medical treatment failed. Vitrectomy seems to be effective in patients with and without previous trabeculectomy with adequate reduction of IOP, although IOP-lowering medication is necessary in nearly all cases to maintain desired IOP.

Byrnes et al reported on a case series report of 20 patients with malignant glaucoma and success of vitrectomy in $50 \%$ of phakic patients and $90 \%$ of pseudophakic eyes. ${ }^{18}$ They recommended combined vitrectomy and crystalline lens extraction to allow removal of the entire anterior vitreous without damaging the lens. They defined success as immediate backward movement of the irislens diaphragm during vitrectomy recovering the aqueous outflow, and deepening of the anterior chamber. This is in contrast to the current study in which success was based on criteria of IOP reduction and medication use. Although the anterior chamber deepened after vitrectomy in all cases of the current study, medication or subsequent IOP-lowering procedures became necessary in the majority of patients to reach target IOP.

A study by Harbour et al, in which surgical outcomes of vitrectomy of ten pseudophakic and 14 phakic eyes were compared, revealed a successful initial vitrectomy in $100 \%$ of seven phakic eyes undergoing concurrent lens extraction and in $71 \%$ of seven phakic eyes without cataract extraction. ${ }^{26} \mathrm{In}$ pseudophakic patients, the initial vitrectomy was successful in $90 \%$ of patients. Therefore, lensectomy during vitrectomy may be considered in cases of dense cataract or inability to deepen the anterior chamber. In the current study, more than two-thirds of patients were pseudophakic at the time of vitrectomy, whereas two patients received cataract extraction during vitrectomy. Thus, two patients remained phakic and also had a successful IOP reduction after deepening of the anterior chamber, but showed a progression of cataract during follow-up.

In the current study, the 23-gauge transconjunctival sutureless vitrectomy was equally effective compared to the standard three-port 20-gauge system regarding reduction of 
IOP and success rate. While the 23-gauge approach is frequently associated with a higher incidence of postoperative hypotony, no differences were found in complication rates between both systems. Furthermore, complications were few in both groups. This is in line with previously published data on complications after vitrectomy for malignant glaucoma mostly encountering transient shallowing of the anterior chamber, hypotony, retinal or choroidal detachment, corneal decompensation, and bleb failure needing surgical revision. ${ }^{18,26}$

Lois et al reported a novel technique of zonulo-hyaloidovitrectomy using a vitreous cutter through a peripheral iridectomy or iridotomy via the anterior chamber in five patients. ${ }^{21}$ Resolution of malignant glaucoma was achieved in all cases during a follow-up of 5.5 months. Lois et al stated that zonulo-hyaloido-vitrectomy via an anterior approach appears to be an option in the treatment of pseudophakic malignant glaucoma and can be safely done by an anterior segment surgeon. ${ }^{21}$

Due to the difficulty in visualization of the anterior hyaloid membrane in phakic eyes, Chen et al introduced a novel technique of videoendoscope-guided fluoresceinassisted vitrectomy without cataract extraction in selected cases of prepresbyopic patients to avoid the need for clear lens extraction. ${ }^{22}$ However, they stated that the limited illumination field of the videoendoscope, when simultaneously used with the vitreous cutter, may contribute to an unintentional touch of the lens during vitrectomy. Previous studies have addressed the importance of lensectomy to achieve desired IOP reduction after the initial vitrectomy since pseudophakic eyes compared to phakic eyes show a higher success rate in terminating malignant glaucoma. ${ }^{18,19,25,26}$

The current study has some limitations. First, retrospective data commonly has more sources of error due to confounding and bias. Second, the sample size was too small to detect small differences between the two groups. It is difficult to collect a large number of cases since malignant glaucoma is a very rare disease. Prospective trials with greater statistical power will be needed to establish surgical methods of malignant glaucoma.

\section{Conclusion}

In summary, pars plana vitrectomy using the 20- and 23-gauge approach is effective for treatment of malignant glaucoma in patients with and without previous filtration surgery. Efficacy regarding reduction of IOP, success, and complications rates was similar in eyes with and without previous trabeculectomy.

\section{Acknowledgments}

This publication was funded by the German Research Foundation (DFG) and the University of Wuerzburg in the funding program Open Access Publishing.

\section{Disclosure}

The authors report no conflicts of interest in this work.

\section{References}

1. SchwartzAL, Anderson DR. Malignant glaucoma in an eye with no antecedent operation or miotics. Arch Ophthalmol. 1975;93(5):379-381.

2. Cashwell LF, Martin TJ. Malignant glaucoma after laser iridotomy. Ophthalmology. 1992;99(5):651-658.

3. Arya SK, Sonika, Kochhar S, Kumar S, Kang M, Sood S. Malignant glaucoma as a complication of Nd:YAG laser posterior capsulotomy. Ophthalmic Surg Lasers Imaging. 2004;35(3):248-250.

4. Hanish SJ, Lamberg RL, Gordon JM. Malignant glaucoma following cataract extraction and intraocular lens implant. Ophthalmic Surg. 1982;13(9):713-714.

5. Rieser JC, Schwartz B. Miotic-induced malignant glaucoma. Arch Ophthalmol. 1972;87(6):706-712.

6. Theelen T, Klevering BJ. Malignant glaucoma following blunt trauma of the eye. Ophthalmologe. 2005;102(1):77-81. German.

7. Ng WT, Morgan W. Mechanisms and treatment of primary angle closure: a review. Clin Experiment Ophthalmol. 2012;40(4):e218-e228.

8. Quigley HA, Friedman DS, Congdon NG. Possible mechanisms of primary angle-closure and malignant glaucoma. J Glaucoma. 2003; 12(2):167-180.

9. Luntz MH, Rosenblatt M. Malignant glaucoma. Surv Ophthalmol. 1987;32(2):73-93.

10. Simmons RJ. Malignant glaucoma. Br J Ophthalmol. 1972;56(3): 263-272.

11. Lippas J. Mechanics and the treatment of malignant glaucoma and the problem of a flat anterior chamber. Am J Ophthalmol. 1964; 57:620-627.

12. Burgansky-Eliash Z, Ishikawa H, Schuman JS. Hypotonous malignant glaucoma: aqueous misdirection with low intraocular pressure. Ophthalmic Surg Lasers Imaging. 2008;39(2):155-159.

13. Ruben S, Tsai J, Hitchings RA. Malignant glaucoma and its management. Br J Ophthalmol. 1997;81(2):163-167.

14. Little BC, Hitchings RA. Pseudophakic malignant glaucoma: Nd:YAG capsulotomy as a primary treatment. Eye (Lond). 1993;7(Pt 1):102-104

15. Halkias A, Magauran DM, Joyce M. Ciliary block (malignant) glaucoma after cataract extraction with lens implant treated with YAG laser capsulotomy and anterior hyaloidotomy. Br J Ophthalmol. 1992;76(9): 569-570.

16. Herschler J. Laser shrinkage of the ciliary processes. A treatment for malignant (ciliary block) glaucoma. Ophthalmology. 1980;87(11): 1155-1159.

17. Momoeda S, Hayashi H, Oshima K. Anterior pars plana vitrectomy for phakic malignant glaucoma. Jpn J Ophthalmol. 1983;27(1):73-79.

18. Byrnes GA, Leen MM, Wong TP, Benson WE. Vitrectomy for ciliary block (malignant) glaucoma. Ophthalmology. 1995;102(9):1308-1311.

19. Sharma A, Sii F, Shah P, Kirkby GR. Vitrectomy-phacoemulsificationvitrectomy for the management of aqueous misdirection syndromes in phakic eyes. Ophthalmology. 2006;113(11):1968-1973.

20. Tsai YY, Tseng SH. Combined trabeculectomy and vitrectomy for pseudophakic malignant glaucoma and extensive peripheral anterior synechia-induced secondary glaucoma. J Cataract Refract Surg. 2004;30(3):715-717.

21. Lois N, Wong D, Groenewald C. New surgical approach in the management of pseudophakic malignant glaucoma. Ophthalmology. 2001;108(4):780-783. 
22. Chen SD, Salmon JF, Patel CK. Videoendoscope-guided fluoresceinassisted vitrectomy for phakic malignant glaucoma. Arch Ophthalmol. 2005;123(10):1419-1421.

23. Shaffer RN. The role of vitreous detachment in aphakic and malignant glaucoma. Trans Am Acad Ophthalmol Otolaryngol. 1954;58(2): 217-231.

24. Chandler PA. A new operation for malignant glaucoma: a preliminary report. Trans Am Ophthalmol Soc. 1964;62:408-424.
25. Tsai JC, Barton KA, Miller MH, Khaw PT, Hitchings RA. Surgical results in malignant glaucoma refractory to medical or laser therapy. Eye (Lond). 1997;11(Pt 5):677-681.

26. Harbour JW, Rubsamen PE, Palmberg P. Pars plana vitrectomy in the management of phakic and pseudophakic malignant glaucoma. Arch Ophthalmol. 1996;114(9):1073-1078.
Clinical Ophthalmology

\section{Publish your work in this journal}

Clinical Ophthalmology is an international, peer-reviewed journal covering all subspecialties within ophthalmology. Key topics include: Optometry; Visual science; Pharmacology and drug therapy in eye diseases; Basic Sciences; Primary and Secondary eye care; Patient Safety and Quality of Care Improvements. This journal is indexed on

\section{Dovepress}

PubMed Central and CAS, and is the official journal of The Society of Clinical Ophthalmology (SCO). The manuscript management system is completely online and includes a very quick and fair peer-review system, which is all easy to use. Visit http://www.dovepress.com/ testimonials.php to read real quotes from published authors. 